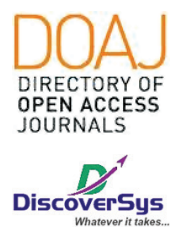

Published by DiscoverSys

\section{Hubungan asfiksia dengan kejang pada neonatus di ruang perinatologi dan NICU RSUD Wangaya kota Denpasar}

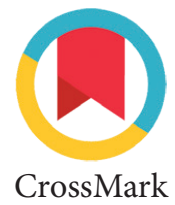

\author{
Ruby Kurniawan, ${ }^{*}$ I Wayan Bikin Suryawan, Made Ratna Dewi
}

\section{ABSTRACT}

Background: Asphyxia is a serious problem in newborns because it can cause high levels of mortality and mortality. Deaths because of asphyxia are around $38 \%$ and are 3rd rank in neonatal deaths. Asphyxia is the most common cause of seizures in newborns with the incidence of 1-3 per 1,000 births. Seizure after asphyxia can occur impaired cognitive and developmental disorders in children. From the relationship, well and proper management of infants with asphyxia can reduce the risk of death and permanent disability due to seizures. Methods: Observational analytic research with cross sectional study design to find out the relationship between asphyxia and seizure in

neonates. The sample of this study is 718 neonates from 0 to 28 days with asphyxia in perinatology and NICU of Wangaya General Hospital Denpasar city from July 2017-July 2018.

Result: The prevalence of neonates with asphyxia are 214 and neonates with seizure are 8 from 214. From this study found a relationship between asphyxia and occurrence of seizure with $p=0,000$.

Conclusion: There is a significant relationship between asphyxia and the occurrence of seizures in neonates.
Bagian/SMF IImu Kesehatan Anak RSUD Wangaya, Bali-Indonesia

*Corresponding: Ruby Kurniawan, Bagian/SMF Ilmu Kesehatan Anak RSUD Wangaya, Bali-Indonesia ruby_kurniawan@ymail.com

Received: 2019-01-17

Accepted: 2019-02-04

Published: 2019-04-01
Keywords: asphyxia, seizure, neonates

Cite This Article: Kurniawan, R., Suryawan, I.W.B., Dewi, M.R. 2019. Hubungan asfiksia dengan kejang pada neonatus di ruang perinatologi dan NICU RSUD Wangaya kota Denpasar. Intisari Sains Medis 10(1): 144-147. D0I: 10.1556/ism.v10i1.398
Latar Belakang: Asfiksia merupakan masalah yang serius pada bayi baru lahir karena dapat menyebabkan kecatatan serta mortalitas yang tinggi. Kematian diakibatkan asfiksia sekitar 38\% dan menjadi peringkat ke 3 kematian pada neonatal. Asfiksia merupakan penyebab tersering terjadinya kejang pada bayi baru lahir dengan kejadian 1-3 per 1.000 kelahiran. Kejang paska terjadinya asfiksia dapat mengakibatkan gangguan kognitif dan perkembangan pada anak. Dilihat hubungannya, tatalaksana yang baik dan tepat pada bayi dengan asfiksia dapat mengurangi resiko kejadian kejang dan mengurangi resiko kecacatan permanen akibat kejang.

Metode: Penelitian observasional analitik dengan rancangan penelitian cross sectional untuk mengetahui adanya hubungan asfiksia dan kejang pada neonatus. Sampel penelitian adalah 718 neonatus usia 0 sampai 28 hari dengan asfiksia dan tanpa asfiksia di ruang perinatologi dan NICU RSUD Wangaya Kota Denpasar sejak bulan Juli 2017 - Juli 2018.

Hasil: Didapatkan prevalensi bayi dengan asfiksia sebanyak 214 dan neonatus dengan kejang sebanyak 8 dari 214 bayi asfiksia. Dari penelitian ini didapatkan hubungan antara asfiksia dengan terjadinya kejang pada neonatus dengan nilai $p=0,000$.

Simpulan: Terdapat hubungan yang signifikan antara asfiksia dengan terjadinya kejang pada neonatus.

Kata kunci: asfiksia, kejang, neonatus

Cite Pasal Ini: Kurniawan, R., Suryawan, I.W.B., Dewi, M.R. 2019. Hubungan asfiksia dengan kejang pada neonatus di ruang perinatologi dan NICU RSUD Wangaya kota Denpasar. Intisari Sains Medis 10(1): 144-147. D0I: 10.1556/ism.v10i1.398

\section{PENDAHULUAN}

Asfiksia didefinisikan sebagai kegagalan untuk bernapas atau ketidakmampuan bayi baru lahir untuk memulai dan mempertahankan respirasi yang adekuat setelah melahirkan. ${ }^{1,2}$ Asfiksia adalah suatu kondisi yang terjadi ketika ada gangguan pertukaran gas-darah, mengakibatkan hipoksemia (kekurangan oksigen) dan hiperkapnia (akumulasi karbon dioksida). ${ }^{1}$ Menurut Ikatan Dokter Anak Indonesia, asfiksia neonatorum adalah kegagalan napas secara spontan dan teratur pada saat lahir atau beberapa saat setelah saat lahir yang ditandai dengan hipoksemia, hiperkarbia dan asidosis.

Asfiksia perinatal dapat mempengaruhi hampir semua organ, tetapi hipoksik-iskemik 
encephalopathy (HIE) adalah kondisi klinis yang paling diteliti dan itu terbebani dengan sekuele paling parah. ${ }^{3}$ Asfiksia merupakan masalah klinis yang serius di seluruh dunia dan berkontribusi besar terhadap kematian dan morbiditas neoatus. ${ }^{1}$

Menurut WHO, 4 juta kematian setahun terjadi akibat asfiksia, 38\% dari semua kematian anak dibawah 5 tahun. Di negara low-income 23\% dari total kematian neonatus terjadi akibat asfiksia. ${ }^{1}$ Sekitar 40\% dari semua kematian balita terjadi pada periode neonatus pada tahun 2008. ${ }^{4}$ Insiden kejadian asfiksia perinatal yaitu 1-6 per 1000 kelahiran bayi hidup dan menjadi peringkat ke 3 penyebab kematian neonatus. ${ }^{3}$ Data survey kesehatan rumah tangga (SKRT) 2010 menyebutkan bahwa penyebab kematian bayi baru lahir di Indonesia di antaranya asfiksia (27\%). ${ }^{5}$ Berdasarkan laporan tahunan Rumah Sakit Umum Pusat (RSUP) Sanglah Denpasar, persentase kejadian asfiksia pada tahun $2010(8,6 \%)$, tahun 2011 (9,3\%), tahun 2012 (11,6\%), tahun 2013 menurun (8,3\%), dan tahun 2014 meningkat kembali $(11,31 \%){ }^{6}$

Kejadian asfiksia merupakan penyebab tersering kejang pada bayi baru lahir. ${ }^{7}$ Definisi kejang sendiri adalah depolarisasi berlebihan sel neuron otak, yang mengakibatkan perubahan yang bersifat paroksismal fungsi neuron (perilaku, fungsi motorik dan otonom) dengan atau tanpa perubahan kesadaran. Kejang pada neonatus dibatasi waktu yaitu kejang yang terjadi pada 28 hari pertama kehidupan (bayi cukup bulan) atau 44 minggu masa konsepsi (usia kronologis + usia gestasi pada saat lahir) pada bayi prematur. ${ }^{8}$ Insiden kejang terjadi pada bayi baru lahir sekitar 1-3 per 1000 bayi lahir.7 Pada penelitian yang dilakukan di Nishtar Medical College and Hospital didapatkan 14 (28\%) bayi lahir asfiksia dengan kejang. ${ }^{9}$

Kejang sering terjadi pada minggu awal kehidupan, dan menjadi tanda pertama disfungsi neurologis, dan merupakan prediktor kuat dari gangguan kognitif dan perkembangan jangka panjang. Bayi baru lahir dengan kejang beresiko untuk kematian neonatus, gangguan neurologis, keterlambatan perkembangan dan kemudian epilepsi. Angka kematian pada tahun pertama kehidupan bayi dengan kejang pada periode neonatus adalah 23\%. Neonatus asfiksia dengan kejang dan memerlukan resusitasi merupakan resiko primer pada kematian. ${ }^{10,11}$

\section{METODE}

Penelitian ini merupakan penelitian analitik observasional dengan desain cross-sectional untuk mengetahui adanya hubungan asfiksia dan kejang pada neonatus. Penelitian ini dilakukan di ruang perinatologi dan NICU RSUD Wangaya Kota Denpasar sejak bulan Juli 2017 - Juli 2018.

Besar sampel mínimum pada penelitian ini adalah 154 sampel. 718 sampel yang memenuhi kriteria inklusi dan eksklusi dipilih menggunakan consecutive sampling. Kriteria inklusi adalah nenonatus (0-28 hari), mengalami asfiksia sedang-berat (APGAR skor $\leq 7$ ). Sedangkan kriteria ekslusi adalah neonatus dengan riwayat trauma, neonatus dengan penyakit infeksi, kelainan kongenital berat (malformasi serebral), kelainan neurologis, kelainan metabolik, sindrom epilepsy, serta data rakam medis yang tidak lengkap.

Sumber data dalam penelitian ini adalah berupa data sekunder yang berasal dari rakam medis pasien. Persetujuan penelitian dan penggunaan rekam medis telah disetujui oleh Kepala bagian SMF Anak di RSUD Wangaya Denpasar. Penelitian ini dilakukan analisis univariat untuk mendeskripsikan karakteristik responden. Analisis bivariat dilakukan untuk menghubungkan antara variabel bebas dengan variabel terikat dengan menggunakan uji fisher dan diolah dengan Statistical Product and Service Solution (SPSS) 23 for Windows.

\section{HASIL}

718 sampel dikelompokkan menjadi 2 kelompok yaitu neonatus dengan asfiksia dan neonatus tidak asfiksia. Pada kelompok dengan asfiksia terdiri dari 214 neonatus dan kelompok tidak asfiksia sebanyak 504. Hasil analisa disajikan dalam tabel meliputi karakteristik sampel berdasarkan usia, jenis kelamin, berat badan lahir, usia gestasi, dan paritas (Tabel 1). Prevalensi neonatus dengan asfiksia selama 1 tahun sebanyak 214 (29\%) meliputi neonatus asfiksia dengan kejang sebanyak $8(3,7 \%)$. Neonatus tidak BBLR yang mengalami asfiksia dengan lebih banyak yaitu 117 (54,7\%) dibandingkan dengan BBLR. Neonatus dengan asfiksia paling banyak terjadi pada ibu dengan kelahiran multipara yaitu 118 (55,1\%). Jika dilihatsesuai umur kehamilan, kejadian lebih sering pada $\geq 37$ minggu sebanyak 123 (57,5\%).

Neonatus kejang dengan asfiksia sebanyak 8 $(3,7 \%)$ dan neonatus kejang dengan tidak asfiksia adalah $1(0,2 \%)$. Hasil uji hipotesis dengan menggunakan uji fisher, didapatkan $\mathrm{p}=0,000$. Karena nilai $\mathrm{p}<0,05$ maka dapat disimpulkan bahwa asfiksia mempunyai hubungan dengan kejadian kejang. Rasio Prevalensi (RP) dihitung Untuk mengetahui besarnya hubungan tersebut. Nilai RP $=18,5$ $(\mathrm{RP}>1)$ dengan IK 95\% = 0,007 - 0063 (IK 95\% tidak mencakup angka 1), berarti asfiksia merupakan faktor risiko atau berpengaruh terhadap kejadian kejang (Tabel 2). 
Tabel 1 Karakteristik sampel

\begin{tabular}{lcc}
\hline Variabel & $\begin{array}{c}\text { Asfiksia } \\
(\mathbf{n = 2 1 4 )}\end{array}$ & Tidak Asfiksia (n=504) \\
\hline Usia (hari)* & $0(0-27)$ & $0(0-28)$ \\
Jenis Kelamin (\%) & & $268(53,2)$ \\
Laki-laki & $122(57,0)$ & $236(46,8)$ \\
$\quad$ Perempuan & $92(43,0)$ & $105(20,8)$ \\
Berat Badan Lahir (\%) & $97(45,3)$ & $399(79,2)$ \\
BBLR & $117(54,7)$ & $194(38,5)$ \\
Tidak BBLR & & $290(57,5)$ \\
Paritas (\%) & $84(39,3)$ & $20(4)$ \\
Primipara & $118(55,1)$ & \\
Multipara & $12(5,6)$ & $78(15,5)$ \\
Grandemultipara & & $425(84,3)$ \\
Usia Gestasi (\%) & $91(42,5)$ & $1(0,2)$ \\
Bayi Kurang Bulan (BKB) & $123(57,5)$ & \\
Bayi Cukup Bulan (BCB) & $0(0)$ & \\
Bayi Lebih Bulan (BLB) & & \\
\hline
\end{tabular}

"Median (range)

Tabel 2 Pengaruh asfiksia terhadap kejang

\begin{tabular}{|c|c|c|c|c|c|}
\hline & & \multicolumn{2}{|c|}{ Kejang } & \multirow{2}{*}{$\begin{array}{c}\text { RP } \\
\text { (IK 95\%) }\end{array}$} & \multirow[b]{2}{*}{ Nilai p } \\
\hline & & Ya & Tidak & & \\
\hline \multirow[t]{2}{*}{ Asfiksia } & $\mathrm{Ya}$ & 8 & 206 & \multirow{3}{*}{$\begin{array}{c}18,5 \\
(0,007- \\
0,063)\end{array}$} & \multirow{3}{*}{0,000} \\
\hline & Tidak & 1 & 503 & & \\
\hline Total & & 9 & 709 & & \\
\hline
\end{tabular}

Tabel 3 Karakteristik neonatus dengan kejang

\begin{tabular}{lcc}
\hline & \multicolumn{2}{c}{ Kejang } \\
\cline { 2 - 3 } Variabel & Asfiksia (n=8) & Tidak Asfiksia (n=1) \\
\hline Jenis Kelamin (\%) & $7(87,5)$ & $1(100)$ \\
Laki-laki & $1(12,5)$ & $0(0)$ \\
Perempuan & & $1(100)$ \\
Berat Badan Lahir (\%) & $1(12,5)$ & $0(0)$ \\
BBLR & $7(87,5)$ & $1(100)$ \\
Tidak BBLR & & $0(0)$ \\
Paritas (\%) & $5(62,5)$ & $0(0)$ \\
Primipara & $3(87,5)$ & $0(0)$ \\
Multipara & $0(0)$ & $1(100)$ \\
Grandemultipara & $1(12,5)$ & $0(0)$ \\
Usia Gestasi (\%) & $7(87,5)$ & $0(0)$ \\
Bayi Kurang Bulan (BKB) & &
\end{tabular}

Tabel 3. menunjukan karakteristik neonatus yang mengalami kejang berdasarkan jenis kelamin, berat badan lahir, usia gestasi dan paritas.

\section{DISKUSI}

Hasil dari penelitian ini menunjukkan adanya hubungan kuat antara asfiksia dengan terjadinya kejang $(\mathrm{p}=0,001)$. Disebutkan bahwa periode neonatus merupakan insiden terbesar terjadinya kejang dan di dalam beberapa penelitian dari Levene dan Trounce, Lien dkk, Mizrahi dan Kellaway bahwa penyebab tersering terjadinya kejang adalah HIE (30-53\%) yang disebabkan akibat asfiksia., ${ }^{8,12}$

Prevalensi bayi dengan asfiksia dalam satu tahun sebanyak 214 (29\%), hampir sama dengan yang didapatkan pada penelitian yang dilakukan oleh Garba Illah dkk yaitu frekuensi bayi dengan asfiksia sebanyak $31 \% .{ }^{1}$ Pada penelitian ini didapatkan bayi dengan kejang sebanyak 8 dari 214 bayi asfiksia $(3,7 \%)$, lebih sedikit dibandingkan dengan penelitian Garba Illah dkk mendapatkan bayi dengan kejang sebanyak 6 dari 47 bayi asfiksia $(12,8 \%)$ dan dari 223 kelahiran selama 1 tahun. ${ }^{1}$ Dalam studi ini, lebih sedikit perempuan yang menderita asfiksia sebanding dengan studi yang dilakukan Port Harcourt, Warri, Iran, Johannesburgm dan India namun berkebalikan dengan yang dilakukan oleh Illah dkk. ${ }^{1}$

Berdasarkan penelitian ini, menunjukkan adanya hubungan signifikan antara asfiksia dengan terjadinya kejang pada neonatus. Hal ini didasarkan pada hasil uji fisher yang diperoleh $p$-value $=0,000$ $(\mathrm{p}<0,05)$. Hasil penelitian ini sama dengan penelitian uji klinis lain, dimana asfiksia merupakan penyebab paling sering terjadinya kejang terlepas dari usia gestasi. ${ }^{13}$ Berdasarkan Evans dan Levene, penyebab kejang lainnya pada neonatus adalah infeksi susunan saraf pusat (17\%), perdarahan intrakranial (10\%), gangguan metabolik akut (5\%), dan idiopatik (2\%). ${ }^{14}$ Sedangkan berdasarkan penelitian oleh Talebian dkk, pada 2015 menemukan penyebab kejang diantaranya HIE (36\%), hiponatremia (12\%), hipoglikemia (11\%), perdarahan intrakranial (11\%), infeksi (10\%), hipokalsemia (8\%), gangguan metabolisme (7\%), anomali struktural (5\%), dan hipomagnesemia (4\%). ${ }^{15}$

Jenis kelamin laki-laki memiliki persentase kejang paling tinggi yaitu $8(88,9 \%)$ sejalan dengan studi yang dilakukan Costea, dan Visa tahun 1995 di Sibiu hingga 2005 yang menemukan frekuensi laki-laki 2 kali lebih tinggi (68,9\%) dibandingkan perempuan. Dalam penelitiannya menyebutkan bahwa dilihat dari berbagai latar belakang seperti usia gestasi kurang, cukup, dan lebih, frekuensi laki-laki 2 kali lebih tinggi. ${ }^{12}$ 
Pada bayi tidak BBLR memiliki kejadian kejang $7(87,5 \%)$ sesuai dengan penelitian Saliba dkk. Tetapi pada penelitian ini secara statistik tidak menunjukkan adanya hubungan yang signifikan antara kejang dengan umur kehamilan dan paritas. ${ }^{16}$

\section{SIMPULAN}

Terdapat hubungan kuat antara nenonatus dengan asfiksia terhadap terjadinya kejang. Diharapkan dapat dilakukan penelitian menggunakan metode yang lebih kuat dan sehingga diperoleh hasil yang lebih mewakili dan dapat direpresentasikan dengan lebih baik pada populasi.

\section{DAFTAR PUSTAKA}

1. Garba Ilah B., Sakajiki Aminu M., Musa A., Bimbo Adelakun M., Oladiran Adeniji A., dan Kolawole T. Prevalence and Risk Factors for Perinatal Asphyxia as Seen at a Specialist Hospital in Gusau, Nigeria. Sub-Saharan African Journal of Medicine. 2015. 2(2), pp. 64-69.

2. Muhammad Aslam H., Saleem S., Afzal R., Iqbal U., Muhammad Saleem S., Waqas Abid Shaikh M., and Shahid N. Risk factors of birth asphyxia, Italian Journal of Pediatrics. 2014. 40(94), pp. 2-9.

3. Antonucci R., Porcella A., and Dolores Piloni M. Perinatal asphyxia in the term newborn. Journal of Pediatric and Neonatal Individualized Medicine. 2014. 3(2), pp. 1-14.

4. World Health Organization (2012) Guidelines on basic newborn resuscitation. [Online]. Available at: http://www. who.int/iris/handle/10665/75157

5. Togaha E., Budhi K., dan Wijayahadi N. Hubungan Antara Derajat Asfiksia dengan Beratnya Hipokalsemia pada Bayi Baru Lahir. Sari Pediatri. 2014. 16(1), pp. 29-34.

6. Widiani A., Kurniati Y., and Windiani T. Faktor Risiko Ibu dan Bayi Terhadap Kejadian Asfiksia Neonatorum di Bali: Penelitian Case Control. Public Health and Preventive Medicine Archive. 2016. 4(2), pp. 12-126.
7. Gillam-Krakauer, dan M Carter B. Neonatal Hypoxia and Seizures. Pediatrics in Review. 2012. 33(9), pp. 387-397.

8. Handryastuti S. Kejang pada Neonatus, Permasalahan dalam Diagnosis dan Tata laksana. Sari Pediatri. 2007 9(2), pp. 112-120.

9. SamadN., FarooqS., Hafeez K., Maryam dan MAftab RafiM. Analysis of Consequences of Birth Asphyxia in Infants: A Regional Study in Southern Punjab, Pakistan. Journal of the College of Physicians and Surgeons Pakistan. 2016. 26(12), pp. 950-953.

10. Heljic S., Uzicanin S., Catibusic dan F Catibusic S. Predictors of Mortality in Neonates with Seizures; a Prospective Cohort Study. Med Arch. 2016. 70(3), pp. 182-185.

11. Wiadnyana, I., Bikin Suryawan, I., Sucipta, A. 2018. Hubungan antara bayi berat lahir rendah dengan asfiksia neonatarum di RSUD Wangaya Kota Denpasar. Intisari Sains Medis 9(2). DOI: 10.15562/ism. v9i2.167.

12. Silverstein FS., dan Jensen FE. Neonatal Seizures. Neurological Progress. 2007. 62, pp. 112-120.

13. Costea RM., dan Visa GA. Particular Features of Neonatal Seizures Populational Study. World Journal of Research and Review. 2016. 3(6), pp. 45-50.

14. Evans D., and Levene M. Neonatal seizures. Arch Dis Child Fetal Neonatal. 1998. 78, pp. 70-75.

15. Talebian A., Jahangiri M., Rabiee M., Masoudi Alavi N., Akbari H., dab Sadat Z. The Etiology and Clinical Evaluations of Neonatal Seizures in Kashan, Iran. Iran J Child Neurol. 2015 9(2), pp. 29-35.

16. Saliba RM., Annegers FJ., Waller DK., Tyson JE., and Mizrahi EM. Risk Factors for Neonatal Seizures: A Population-based Study, Harris County, Texas, 19921994. American Journal of Epidemiology. 2001. 154(1), pp. 14-20.

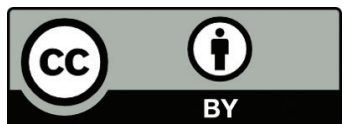

This work is licensed under a Creative Commons Attribution 